proportion of 2-year-olds) is used when $R_{1}$ is unavailable or has large variance. Recruitment indices are calculated using the maximum-likelihood method ${ }^{14,27}$. Chlorophyll- $a$ data are integrated $0-100 \mathrm{~m}$ values. Salp biomass is derived from the internal body length: $\mathrm{C}$ relationship ${ }^{18}\left(\right.$ carbon $=0.001336 \times$ length $\left.^{2.331}\right)$. Krill biomass is derived from the relationships between standard length and wet weight (ref. 28) $\left(\right.$ weight $=0.00158 \times$ length $^{3.40}$ ) and wet weight and carbon (ref. 9) $\left(\right.$ carbon $=72.77 \times$ weight $\left.^{1.0242}\right)$. Sea-ice coverage is based on daily ice charts derived from passive microwave imagery by the U.S. National Snow and Ice Data Center ${ }^{29}$. Annual sea-ice indices for an area of $1,250,000 \mathrm{~km}^{2}$ on the west side of the Antarctic Peninsula were determined by numerical integration of monthly estimates of ice cover for each calendar year, and expressed in units of $10^{6} \mathrm{~km}^{2}$ months $\mathrm{s}^{30}$. The relationship between air temperature and the regional sea-ice index (Fig. 2) is based on mean monthly air temperatures from Palmer Station or from Faraday, adjusted as ref. 21. The regression, temperature $=-6.514+0.0505$ (for years between 1947 and 1996) $(F=13.98, P=0.001)$ is similar to that from 1944 to 1987 (ref. 12). The correlation between the regional sea-ice index and air temperature is highly significant $(n=17$, Kendall's $T=-0.66, P<0.001)$.

Received 6 January; accepted 21 April 1997.

1. Marr, J. W. S. The natural history and geography of the Antarctic krill (Euphausia superba Dana). Discovery Rep. 32, 33-464 (1962).

2. Mackintosh, N. A. Distribution of post-larval krill in the Antarctic. Discovery Rep. 36, 95-156 (1973). . Quetin, L. B. \& Ross, R. M. Behavioral and physiological characteristics of the Antarctic krill, Euphausia superba. Am. Zool. 31, 49-63 (1991).

4. Nicol, S. in Antarctic Science: Global Concerns (ed. Hempel, G.) 144-166 (Springer, Berlin, 1994).

5. Kock, K.-H. \& Shimadzu, Y. in Southern Ocean Ecology: The BIOMASS Perspective (ed. El-Sayed, S. Z 287-312 (Cambridge Univ. Press, 1994).

6. Marchant, H. J. \& Murphy, E. J. in Southern Ocean Ecology: The BIOMASS Perspective (ed. El-Sayed, S Z.) 267-285 (Cambridge Univ. Press, 1994)

Foxton, P. The distribution and life-history of Salpa thompsoni Foxton with observations on a related species, Salpa gerlachei Foxton. Discovery Rep. 34, 1-116 (1966).

8. Casareto, B. E. \& Nemoto, T. Salps of the Southern Ocean (Australian sector) during the 1983-84 summer, with special reference ot the species Salpa thompsoni, Foxton 1961. Mem. Natl Inst. Polar Res. (Spec. issue) 40, 221-239 (1986)

9. Nishikawa, J. et al. Distribution of salps near the South Shetland Islands during austral summer 1990-1991 with special reference to krill distribution. Polar Biol. 15, 31-39 (1995).

10. Gon, O. \& Heemstra, C. Fishes of the Southern Ocean (J.L.B. Smith Institute of Ichthyology Grahamstown, 1990)

11. Siegel, V. \& Loeb, V. Recruitment of Antarctic krill Euphausia superba and possible causes for its variability. Mar. Ecol. Prog. Ser. 123, 45-56 (1995).

12. Fraser, W. R., Trivelpiece, W. Z., Ainely, D. G. \& Trivelpiece, S. G. Increases in Antarctic penguin populations: reduced competition with whales or a loss of sea ice due to global warming? Polar Biol. 11, 525-531 (1992).

13. Fraser, W. R. \& Trivelpiece, W. Z. in Foundations for Ecological Research West of the Antarctic Peninsul (eds Ross, R. M., Hofmann, E. E. \& Quetin, L. B.). American Geophysical Union Research Series 70, 257-272 (1996)

14. Siegel, V., de la Mare, W. \& Loeb, V. Longterm monitoring of krill recruitment and abundance indices in the Elephant Island Area (Antarctic Peninsula). CCAMLR Science (in the press).

15. Siegel, V. Age and growth of Antarctic euphausiacea (Crustacea) under natural conditions. Mar. Biol. 96, 483-495 (1987)

16. Fortier, L., Lè Fevre, J. \& Legendre, L. Export of biogenic carbon to fish and to the deep ocean: the role of large planktonic microphages. J. Plankton Res. 16, 809-839 (1994).

17. Smetacek, V., Scharek, R. \& Nöthig, E.-M. in Antarctic Ecosystems: Ecological Change and Conservation (eds Kerry, K. R. \& Hempel. G.) 103-114 (Springer, Berlin, 1990).

18. Huntley, M. E., Sykes, P. F. \& Marin, V. Biometry and trophodynamics of Salpa thompsoni Foxton (Tunicata: Thaliacea) near the Antarctic Peninsula in austral summer, 1983-1984. Polar Biol. 10, 5970 (1989).

19. Weber, L. H. \& El-Sayed, S. Z. Contributions of the net, nano- and picoplankton to the phytoplankton standing crop and primary productivity in the Southern Ocean. J. Plankton Res. 9, 973-994 (1987).

20. King, J. C. Recent climate variability in the vicinity of the antarctic peninsula. Int. J. Climatol. 14, 357 369 (1994)

21. Smith, R. C., Stammeriohn, S. E. \& Baker, K. S. in Foundations for Ecological Research West of the Antarctic Peninsula (eds Ross, R. M., Hofmann, E. E. \& Quetin, L. B.) AGU Res. Ser. 70, 105-122 (1996).

22. Stark, P. Climatic warming in the central Antarctic Peninsula area. Weather 49, 215-220 (1994).

23. Siegel, V. in Antarctic Ocean and Resources Variability (ed. Sahrhage, D.) 219-230 (Springer, Berlin 1988).

24. Trivelpiece, W. Z. \& Trivelpiece, S. G. The impact of global warming on Antarctica's krill-dependent predator populations. Ecology (submitted).

25. Stammerjohn, S. E. \& Smith, R. C. in Foundations for Ecological Research West of the Antarcti Peninsula (eds Ross, R. M., Hofmann, E. E. \& Quetin, L. B.) AGU Res. Ser. 70, 81-104 (1996).

26. CCAMLR Report of the Fifteenth Meeting of the Scientific Committee. SC-CCAMLR-XV (Commiss. Conserv. Antarc. Mar. Living Resources, Hobart, Tasmania, 1996).

27. de la Mare, W. K. Estimating krill recruitment and its variability. CCAMLR Sci. 1, 55-69 (1994).

28. Kils, U. Swimming behaviour, swimming performance, and energy balance of Antarctic krill Euphausia superba. BIOMASS Sci. Ser. 3, 1-233 (1981).

29. National Snow and Ice Data Center, University of Colorado at Boulder (nsidc@kryos.colorado.edu).

30. Hewitt, R. P. Areal and seasonal extent of sea ice cover off the northwestern side of the Antarctic Peninsula: 1979 through 1996. CCAMLR Sci. (in the press).

Acknowledgements. We thank S. Bros, G. Cailliet, D. Outram, R. Phleger, E. Shulenberger, M. White an K. Wishner for comments, and S. Nocol for helping to improve the manuscript. This work was supported by the National Oceanic and Atmospheric Administration US. Antarctic Marine Living Resources Program. Additional support came for the National Science Foundation (W.F., W.T. and S.T.) and the Institut für Seefischerei (VS.).

Correspondence and requests for materials should be addressed to V.L. (e-mail: loeb@mlml.calstate.edu).

\section{Corticofugal modulation of frequency processing in bat auditory system}

\author{
Yunfeng Zhang, Nobuo Suga \& Jun Yan
}

Department of Biology, Washington University, 1 Brookings Drive, St Louis, Missouri 63130, USA

Auditory signals are transmitted from the inner ear through the brainstem to the higher auditory regions of the brain. Neurons throughout the auditory system are tuned to stimulus frequency, and in many auditory regions are arranged in topographical maps with respect to their preferred frequency. These properties are assumed to arise from the interactions of convergent and divergent projections ascending from lower to higher auditory areas ${ }^{1}$; such a view, however, ignores the possible role of descending projections from cortical to subcortical regions ${ }^{2-10}$. In the bat auditory system, such corticofugal connections modulate neuronal activity to improve the processing of echo-delay information ${ }^{11,12}$, a specialized feature. Here we show that corticofugal projections are also involved in the most common type of auditory processing, frequency tuning. When cortical neurons tuned to a specific frequency are inactivated, the auditory responses of subcortical neurons tuned to the same frequency are reduced. Moreover, the responses of other subcortical neurons tuned to different frequencies are increased, and their preferred frequencies are shifted towards that of the inactivated cortical neurons. Thus the corticofugal system mediates a positive feedback which, in combination with widespread lateral inhibition, sharpens and adjusts the tuning of neurons at earlier stages in the auditory processing pathway.

The moustached bat, Pteronotus parnellii, emits orientation sounds (biosonar pulses) that contain a long constant-frequency component $(\sim 61 \mathrm{kHz})$ suited for velocity (Doppler) measurement. The bat uses velocity information carried by the $61-\mathrm{kHz}$ component for hunting flying insects ${ }^{13,14}$. Accordingly, its auditory system, from the periphery to the cortex, contains many neurons that are sharply tuned to this frequency for fine frequency analysis ${ }^{15,16}$. The sharp frequency-tuning curves in the central auditory system are sculpted by lateral inhibition ${ }^{17-21}$. The area of the primary auditory cortex that is tuned to $\sim 61 \mathrm{kHz}$ receives input from part of the thalamus ${ }^{22}$ and has a frequency axis ${ }^{16,17}$ like that of the primary auditory cortex of rats, cats and monkeys ${ }^{23}$.

We studied the effect of inactivation of the corticofugal system on the auditory responses of subcortical neurons (32 thalamic and 27 collicular neurons) that are tuned to frequencies between 60.47 and $62.30 \mathrm{kHz}$. Lidocaine (a local anaesthetic) always had an effect on the subcortical neurons when applied to cortical neurons tuned to these frequencies but had no effect when applied to cortical neurons tuned to frequencies outside this range (such as 34,57 or $84 \mathrm{kHz}$ ). The effect of Lidocaine when the 'best frequency' of a subcortical neuron and that of inactivated cortical neurons were 'matched' (were within $\pm 0.20 \mathrm{kHz}$ ) was different from when they were 'unmatched' (different by more than $0.20 \mathrm{kHz}$ ).

Cortical inactivation decreased the auditory responses of matched subcortical neurons (Fig. 1A,b) without shifting their frequency-response curves (Fig. 1A,d). In contrast, cortical inactivation increased the auditory responses of unmatched subcortical neurons and shifted the best frequency towards that of the inactivated cortical neurons. Recovery of normal tuning took 1.5-3.2 h; such an increase and recovery is shown for two unmatched thalamic neurons that had best frequencies $0.30 \mathrm{kHz}$ lower (Fig. 1B) or $0.68 \mathrm{kHz}$ higher (Fig. 1C) than the inactivated cortical neurons. The frequency-response curve shown in Fig. 1B,d (filled circles) 
indicates that the increase in the response of the thalamic neuron occurred mostly for frequencies higher than the best frequency $(60.67 \mathrm{kHz})$. Because of this frequency-dependent increase, the frequency-response curve was shifted towards higher frequencies, that is, towards the best frequency of the inactivated cortical neurons $(P<0.002)$. When the thalamic best frequency was higher than the cortical best frequency, the shift in the thalamic best frequency was toward lower frequencies (Fig. 1C,d, filled circles; $P<0.004)$.

Thalamic and collicular neurons normally showed large variations in the shape of frequency-tuning curves (Fig. 2A-D). Cortical inactivation shifted the frequency-tuning curves of unmatched subcortical neurons, together with their best frequencies, along the frequency axis, but evoked little change in either minimum threshold or best amplitude. The shifted curves returned to the control condition in 1.5-3.2 $\mathrm{h}$. This parallel shift and recovery in the frequency-tuning curves are shown for two thalamic (Fig. 2A,B) and two collicular (Fig. 2C,D) neurons that had best frequency lower (Fig. 2A,D) or higher (Fig. 2B,C) than those of inactivated cortical neurons. Although the shift was parallel, a small amount of broadening in tuning-curve width was noticed in some subcortical neurons (for example, at $40-60 \mathrm{~dB}$ sound pressure level in Fig. $2 \mathrm{C})$. The amount of broadening varied with stimulus amplitude: the
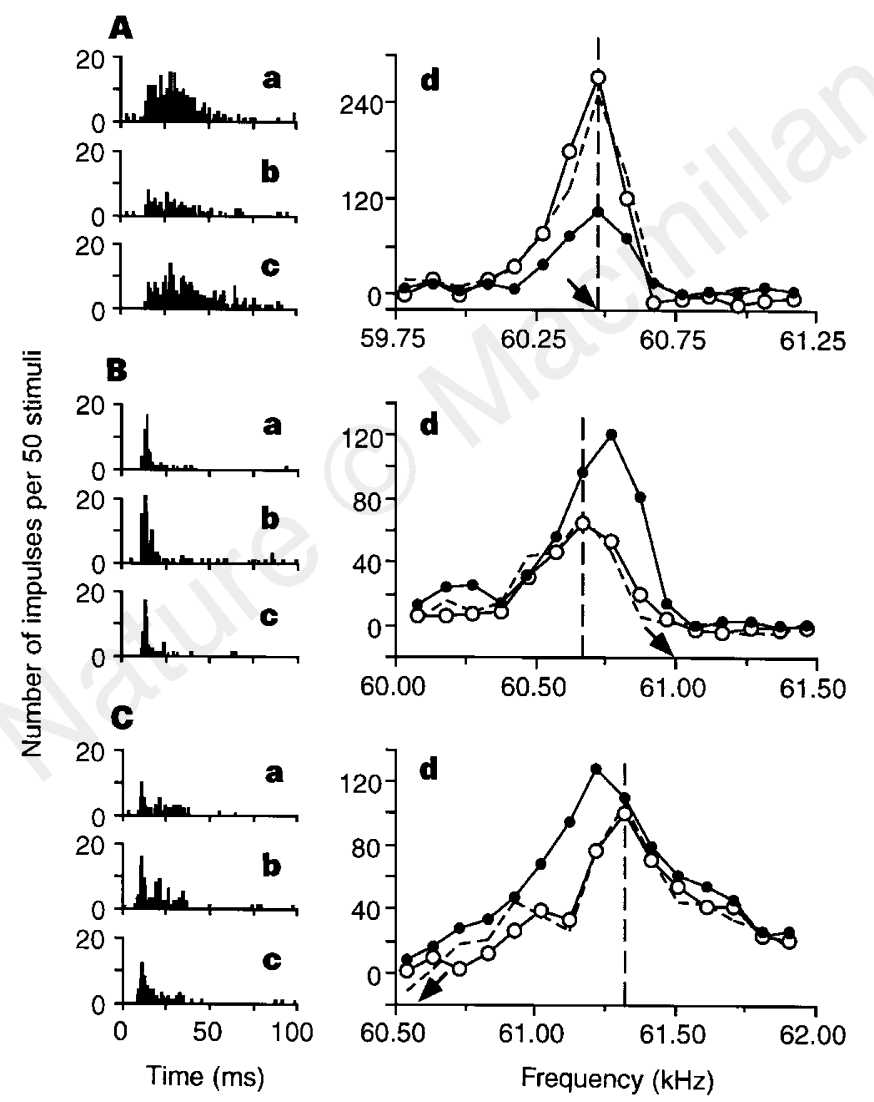

Figure 1 Auditory responses (a-c) and frequency-response curves (d) of three single thalamic neurons obtained before (a; control, open circles in $\mathbf{d})$, during (b; Lidocaine application, $90 \mathrm{nl}, 1.0 \%$, filled circles in $\mathbf{d}$ ) and after (c; recovery, broken line in $\mathbf{d}$ ) a focal inactivation of cortical neurons. The best frequencies of cortical and thalamic neurons paired for the experiments, respectively, were: A, 60.47 and $60.47 \mathrm{kHz} ; \mathbf{B}, 60.97$ and $60.67 \mathrm{kHz}$, and $\mathbf{C}, 60.64$ and $61.32 \mathrm{kHz}$. The effects of the inactivation of the cortical neurons on the thalamic neurons were different depending on the relationship in best frequency between the cortical and thalamic neurons. The vertical broken lines and arrows indicate the best frequencies of the thalamic and cortical neurons, respectively. higher the stimulus level, the greater the broadening (Fig. 2E).

After cortical inactivation, thalamic neurons showed a larger change in response magnitude than did collicular neurons. The decrease in the response of matched neurons was 2.6 times larger for the thalamic neurons $(54.2 \pm 14.5 \%$ (mean \pm s.d.), $n=4$ ) than for the collicular neurons $(20.8 \pm 8.90 \%, n=4)$ (Fig. 3A,C, open triangles; $P<0.05)$. The increase in the response of unmatched neurons measured at the best frequencies shifted by the cortical inactivation was 1.8 times larger for the thalamic neurons (104 $\pm 59.5 \%, \quad n=28)$ than for the collicular neurons (59.0 $\pm 39.5 \%, n=23$ ) (Fig. 3A,C, filled circles; $P<0.01$ ).

After cortical inactivation, best frequencies did not shift for subcortical matched neurons (Fig. 3B,D, open triangles), but shifted for subcortical unmatched neurons: the larger the difference in best frequency, the larger the shift (Fig. 3B,D, filled circles). The rate of shift per difference in best frequency was 0.33 for the thalamic neurons and 0.18 for the collicular neurons. Therefore, the magnitude of best-frequency shift was 1.8 times larger for the thalamic neurons than for the collicular neurons $(P<0.05)$. These data indicate that the decrease or increase in response and the shift in frequency tuning of the subcortical neurons occur in both the colliculus and the thalamus through the corticocollicular and corticothalamic projections.
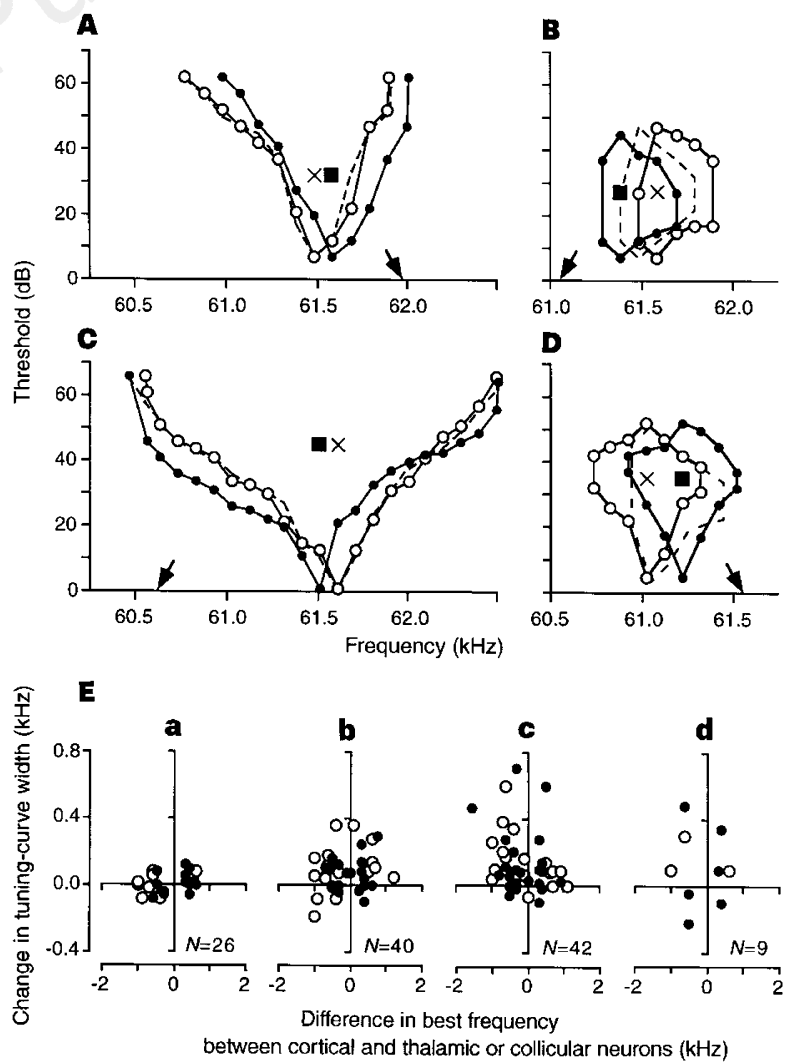

Figure 2 Changes in the frequency-tuning curves of thalamic ( $\mathbf{A}$ and $\mathbf{B}$ ) and collicular neurons ( $\mathbf{C}$ and $\mathbf{D}$ ) by a focal inactivation of cortical neurons. The best frequencies of the inactivated cortical neurons are indicated by the arrows. The curves were measured before (control, open circles), during (filled circles) and after (recovery, broken lines) the cortical inactivation. The tuning curves shift towards the best frequencies of inactivated cortical neurons. Crosses and squares indicate the best amplitudes measured before and during the cortical inactivation, respectively. $\mathbf{E}$, Changes in the widths of frequency-tuning curves at 10 (a), 30 (b), 50 (c) and $70 \mathrm{~dB}$ (d) above minimum threshold evoked by a focal inactivation of cortical neurons. Results are for thalamic (filled circles) and collicular (open circles) neurons. 
In our experiments, the number of matched subcortical neurons studied was small $(n=8)$. However, the corticofugal effects are strikingly consistent and are, without exception, completely opposite to those on the 51 unmatched subcortical neurons (Fig. 3A,C). Furthermore, the data from the matched neurons (no best-frequency shifts) and those from the unmatched neurons (bestfrequency shifts) fit the same linear function as shown by the regression lines in Fig. 3, which cross the zero-shift line at a zero best-frequency difference. Therefore, the results justify our conclusion that, in the normal condition, cortical neurons augment the responses of matched subcortical neurons, but suppress those of unmatched subcortical neurons and shift their frequency-tuning curves away from those of the cortical neurons.

The frequency axis in the cortical area tuned to $61 \mathrm{kHz}$ is radial. Best frequency changes at a rate of $\sim 3.3 \mathrm{kHz} \mathrm{mm}^{-1}$ for frequencies between 61.0 and $61.5 \mathrm{kHz}$ along the rostrocaudal axis of this cortical area ${ }^{16,17,24}$. This corresponds to a rate of $\sim 66 \mathrm{~Hz}$ per minicolumn (a minicolumn is a slab formed by neurons tuned to an identical best frequency), because each minicolumn is $\sim 20 \mu \mathrm{m}$ wide. The best frequencies of cortical neuron that had a positive feedback effect on a subcortical neurons were within a range of $\pm 0.2 \mathrm{kHz}$ of the best frequency of the subcortical neuron. This indicates that a subcortical neuron receives positive feedback from cortical neurons in a maximum of six minicolumns. Since Lidocaine applied to the cortex would spread to some extent, it is most likely that a subcortical neuron receives positive feedback from only one or a few minicolumns.

Our data indicate that individual subcortical and, perhaps, cortical neurons have multiple excitatory inputs that differ slightly in best frequency but are otherwise similar in frequency and amplitude tuning. Second, our data indicate that cortical neurons select particular excitatory inputs through a highly focused positive feedback that is associated with widespread lateral inhibition; that
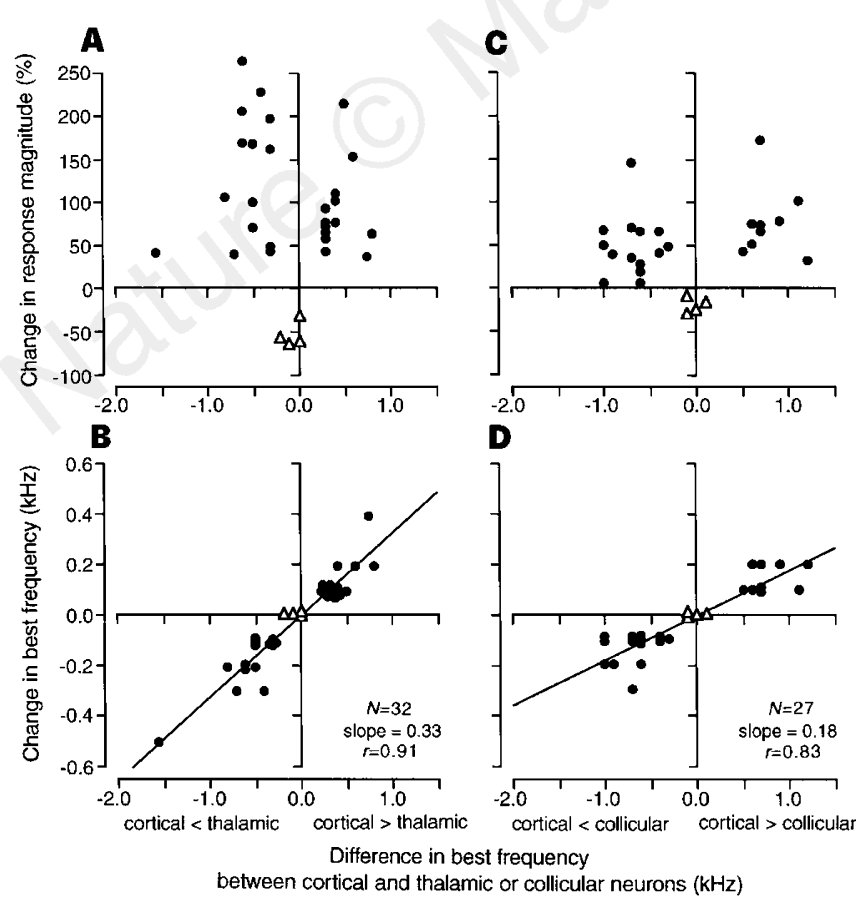

Figure $\mathbf{3}$ Changes in response magnitude ( $\mathbf{A}$ and $\mathbf{C}$ ), and best frequency (B and D) of thalamic ( $\mathbf{A}$ and $\mathbf{B}$ ) and collicular neurons (C and $\mathbf{D})$ evoked by a focal inactivation of cortical neurons. Triangles and filled circles represent the data obtained from matched and unmatched subcortical neurons, respectively. The filled circles in $\mathbf{A}$ and $\mathbf{C}$ represent the increase in response magnitude at the best frequencies shifted by cortical inactivation. The regression line, its slope, and correlation coefficient $(r)$ are shown in $\mathbf{B}$ and $\mathbf{D}$. is, they perform 'egocentric selection' through the corticofugal system. Third, egocentric selection shifts the frequency-tuning curves of unmatched subcortical neurons, and sharpens some of these curves. Fourth, egocentric selection enhances the contrast in the neural representation of auditory information. Finally, our data indicate that egocentric selection is one of the fundamental functions of the auditory cortex, because it is found for frequencydomain processing, which is shared by all higher vertebrates, as well as for time (echo-delay)-domain processing which may be unique to the auditory system of the bat.

The effects of a 100-nA, 0.2-ms electrical stimulation of the cortex on subcortical neurons lasted $\sim 2 \mathrm{~h}$ when it was delivered to the cortex at a rate of 6 stimulations per second for $11 \mathrm{~min}$ (ref. 12). The effects of Lidocaine were apparent for $1.5-3.2 \mathrm{~h}$ even though only a small amount was applied. Egocentric selection works with a slow time course. When an identical signal is received repeatedly by an animal, egocentric selection will increase the neural representation of this frequently occurring signal in the colliculus, thalamus and cortex. When a signal is received only rarely by the animal, however, the neural representation will decrease for this signal. Therefore, we hypothesize that egocentric selection is involved in long-term changes in the overall functional organization of the central auditory system ${ }^{25-27}$.

Almost all auditory neurons are tuned to particular frequencies. Therefore, all signal processing, including ranging and sound localization, is presumably modulated in the frequency domain by the corticofugal projections originating in the primary auditory cortex. In addition, signal processing in other domains, such as echo delay, are modulated more specifically by the corticofugal projections originating from specialized cortical area. The descending system originating from the cortex eventually ends in the cochlear hair cells. It is not yet known whether egocentric selection occurs in the subcollicular nuclei and cochlea.

\section{Methods}

General. The preparation of animals and recording of action potentials were as described $^{28}$. In four moustached bats not anaesthetized, the best frequencies of multiple neurons were first measured at 4-5 loci in the area of the primary auditory cortex tuned to $60.47-62.30 \mathrm{kHz}$ (ref. 24). The best frequency of a single neuron in the ventral division of the medial geniculate body in the thalamus or the dorsoposterior division of the inferior colliculus in the midbrain was measured. To inactivate one of the cortical loci where best frequencies were measured, $90 \mathrm{nl}$ of $1.0 \%$ Lidocaine (local anaesthetic) was injected into the $\sim 900-\mu \mathrm{m}$-thick cortex at a depth of $600-700 \mu \mathrm{m}$ by using a mechanical micro-injection unit. Responses of the single subcortical neuron to tone bursts of different frequencies and amplitudes were collected with a computer before, during and after the cortical inactivation. A $t$-test was used to establish whether the difference in auditory response was statistically significant before and after Lidocaine or between thalamic and collicular neurons. Acoustic stimuli. To measure a frequency-response curve, a computercontrolled frequency scan was presented 50 times at a best amplitude excite to a given neuron. The frequency scan consisted of 21 time blocks: in the first 20 blocks, the frequency of a tone burst lasting $23 \mathrm{~ms}$ was changed by $0.1-\mathrm{kHz}$ steps across the best frequency of a given neuron; in the 21st (last) block, no stimulus was presented. The duration of each block was $200 \mathrm{~ms}$. To measure a frequencytuning curve, the frequency scan consisted of 33 time blocks, in the first 32 of which frequency was changed by $0.1-\mathrm{kHz}$ steps. This frequency scan was presented 5 times at a given amplitude, and after every 5 frequency scans the amplitude of a tone burst was changed from $101 \mathrm{~dB}$ to $1 \mathrm{~dB}$ in $5-\mathrm{dB}$ steps. Thus the frequency-amplitude scan consisted of $33 \times 21$ blocks.

Data acquisition. The responses of a neuron during the frequency or frequency-amplitude scan were continuously monitored as rasters and as an array of peristimulus-time histograms displayed on a computer screen. Action potentials were also continuously monitored by comparing incoming action potentials with the template of an action potential recorded at the beginning of the continuous recording with a digital storage oscilloscope. Data were used for off-line analysis as long as the shape of action potentials matched the template. 
Data processing. The criterion for threshold was the boundary between a block showing one response (action potential) per five trials and a block showing no response per five trials. In unanaesthetized bats the response magnitude and background discharge rate of thalamic and collicular neurons fluctuated to some extent. Therefore, the threshold was determined with additional criteria. If a given block showed at least one response per five trials, it was interpreted to be within an excitatory area demarcated by a tuning curve. If it showed no response per five trials, but the adjacent blocks, away from the excitatory area, showed at least one response per five trials, the given block was put within the excitatory area. Because auditory responses always occurred within a time window of $50 \mathrm{~ms}$ with relatively constant latencies ranging between 5 and $12 \mathrm{~ms}$, and background discharge rate was low $\left(0.58 \pm 0.32 \mathrm{~s}^{-1}\right.$ for 17 collicular neurons and $0.85 \pm 0.43 \mathrm{~s}^{-1}$ for 16 thalamic neurons), auditory responses were easily distinguished from background discharges.

We established the criteria for a shift in frequency tuning as follows. If frequency-response or frequency-tuning curves shifted by cortical inactivation with Lidocaine did not recover to more than $50 \%$ of their earlier value they were excluded from our analysis. The fact that almost all curves shifted by Lidocaine recovered by more than $50 \%$ indicates that the shift was significant. To ensure that the shift was significant we used the following procedure. For individual frequency-response curves, a weighted average frequency (best frequency) was calculated for the summed responses to 5 consecutive frequency scans. We obtained 10 such values to calculate the mean \pm s.d. We used a twotailed, paired $t$-test to determine whether or not the weighted average frequencies (best frequencies) obtained for control and Lidocaine conditions were significantly different (at $P<0.01$ ). Frequency-tuning curves were based upon the threshold measurement, so s.d. could not be calculated for each data point. We therefore applied the following criterion: shifts in best frequencies and frequency-tuning curves evoked by Lidocaine were considered to be significant if the shift in best frequency was accompanied by shifts of more than $75 \%$ of the data points in the same direction as that of the best-frequency shift.

Received 31 December 1996; accepted 25 April 1997.

1. Suga, N. Cortical computational maps for auditory imaging. Neural Networks 3, 3-21 (1990).

2. Huffman, R. F. \& Henson, O. W. Jr The descending auditory pathway and acousticomotor system: connections with the inferior colliculus. Brain Res. 15, 295-323 (1990).

3. Andersen, R. A. et al. The topographic organization of corticocollicular projections from physiologically identified loci in the AI, AII, and anterior auditory cortical field of the cat. J. Comp. Neurol. 191, 479-494 (1980).

4. Herbert, H. et al. Topography of projections from the auditory cortex to the inferior colliculus in the rat. J. Comp. Neurol. 304, 103-122 (1991).

Massopust, L. C. Jr \& Ordy, J. M. Auditory organization of the inferior colliculus in the cat. Exp. Neurol. 6, 465-477 (1962).

6. Andersen, P. et al. Corticofugal facilitation of thalamic transmission. Brain Behav. Evol. 6, 170-184 (1972).

Ryugo, D. K. \& Weinberger, N. M. Corticofugal modulation of the medial geniculate body. Exp. Neurol. 51, 377-391 (1976).

8. Mitani, A. et al. Effects of simulation of the primary auditory cortex upon colliculogeniculate neurons in the inferior colliculus of the cat. Neurosci. Lett. 42, 185-189 (1983).

9. Sun, X. et al. Corticofugal influences on the responses of bat inferior colliculus to sound stimulation. Brain Res. 495, 1-8 (1989).

10. Villa, A. P. E. et al. Corticofugal modulation of the information processing in the auditory thalamus of the cat. Exp. Brain Res. 86, 506-517 (1991).

11. Suga, N. et al. in Active Hearing (eds Ottoson, A. F. D. \& Ulfendahl, M.) 13-30 (Pergamon, London, 1995)

12. Yan, J. \& Suga, N. Corticofugal modulation of time-domain processing of biosonar information in bats. Science 273, 1100-1103 (1996).

13. Johnson, R. A. et al. Detection of insect wing beats by the bat, Pteronotus parnellii. J. Acoust. Soc. Am. 55, S53 (1974).

14. Goldman, L. J. \& Henson, O. W. Jr Prey recognition and selection by the constant frequency bat, Pteronotus p. parnellii. Behav. Ecol. Sociobiol. 2, 411-419 (1977).

15. Suga, N. et al. Peripheral specialization for fine analysis of Doppler-shifted echoes in the auditory system of the "CF-FM" bat Pteronotus parnelli. Exp. Biol. 63, 161-192 (1975)

16. Suga, N. \& Jen, P. H. S. Disproportionate tonotopic representation for processing species-specific CFFM sonar signals in the mustahced bat auditory cortex. Science 194, 542-544 (1976).

17. Suga, N. \& Manabe, T. Neural basis of amplitude-spectrum representation in auditory cortex of the mustached bat. J. Neurophysiol. 47, 225-255 (1982).

18. Suga, N. \& Tsuzuki, K. Inhibition and level-tolerant frequency-tuning curves in the auditory cortex of the mustached bat. J. Neurophysiol. 53, 1109-1145 (1985).

19. Yang, L. et al. GABAergic circuits sharpen tuning curves and modify response properties in the mustached bat inferior colliculus. J. Neurophysiol. 68, 1760-1774 (1992).

20. Suga, N. et al. Sharpening of frequency tuning by inhibition in the thalamic auditory nucleus of the mustached bat. J. Neurophysiol. 77, 2098-2114 (1997).

21. Suga, N. Sharpening of frequency tuning by inhibition in the central auditory system: Tribute to Yasuji Katsuki. Neurosci. Res. 21, 287-299 (1995)

22. Olsen, J. F. thesis, Washington University (1986).

23. Winer, J. A. in The Mammalian Auditory Pathway: Neuroanatomy (eds Webster, D. B., Popper, A. N. \& Fay, R. R.) 222-410 (Springer, New York, 1992).

24. Suga, N. et al. The personalized auditory cortex of the mustached bat: adaptation for echolocation. $J$ Neurophysiol. 58, 643-654 (1987).
25. Edeline, J. M. \& Weinberger, N. M. Subcortical adaptive filtering in the auditory system: associative receptive field plasticity in the dorsal medial geniculate body. Behav. Neurosci. 105, 154-175 (1991) 26. Edeline, J. M. \& Weinberger, N. M. Associative returning in the thalamic source of input to the amygdala and auditory cortex: receptive field plasticity in the medial division of the medial geniculate body. Behav. Neurosci. 106, 81-105 (1992).

27. Edeline, J. M. et al. Rapid development of learning-induced receptive field plasticity in the auditory cortex. Behav. Neurosci. 107, 539-551 (1993)

28. Suga, N. et al. Specificity of combination-sensitive neurons for processing of complex biosonar signals in the auditory cortex of the mustached bat. J. Neurophysiol. 49, 1573-1626 (1983).

Acknowledgements. We thank the Natural Resource Conservation Authority and the Ministry of agriculture of Jamaica for allowing us to collect and export the moustached bats used in our research. We thank S. Kuwada, W. E. ONeill, J. F. Olsen, D. C. Fitzpatrick and A. Kadir for helpful comments.

\section{Congenital leptin deficiency is associated with severe early-onset obesity in humans}

\author{
Carl T. Montague ${ }^{\star} \dagger$, I. Sadaf Farooqi ${ }^{*} \dagger \neq$, \\ Jonathan P. Whitehead ${ }^{\star} \ddagger$, Maria A. Soos ${ }^{\star} \ddagger$, Harald Rau ${ }^{\star} \ddagger$, \\ Nicholas J. Wareham $₫$, Ciaran P. Sewter ${ }^{\star}$, \\ Janet E. Digby $\ddagger$, Shehla N. Mohammed\|, Jane A. Hurstg, \\ Christopher H. Cheetham\#, Alison R. Earley\#, \\ Anthony H. Barnett \\ \& Stephen O'Rahilly $¥$
}

University of Cambridge, Departments of ${ }^{\star}$ Medicine, $\ddagger$ Clinical Biochemistry and $\$$ Community Medicine, Addenbrooke’s Hospital, Hills Road,

Cambridge CB2 2QR, UK

II South Thames Regional Genetics Centre (East), Guy's Hospital, London SE1 9RT, UK

I Oxford Regional Genetics Service, Churchill Hospital, Oxford OX3 7LJ, UK

\# Wycombe General Hospital, Queen Alexandra Road, High Wycombe,

Buckinghamshire HP11 2TT, UK

Department of Medicine, University of Birmingham and Birmingham

Heartlands Hospital, Birmingham B9 5SS, UK

$\dagger$ These authors contributed equally to this study.

The extreme obesity of the obese (ob/ob) mouse is attributable to mutations in the gene encoding leptin ${ }^{1}$, an adipocyte-specific secreted protein which has profound effects on appetite and energy expenditure. We know of no equivalent evidence regarding leptin's role in the control of fat mass in humans. We have examined two severely obese children who are members of the same highly consanguineous pedigree. Their serum leptin levels were very low despite their markedly elevated fat mass and, in both, a homozygous frame-shift mutation involving the deletion of a single guanine nucleotide in codon $\mathbf{1 3 3}$ of the gene for leptin was found. The severe obesity found in these congenitally leptindeficient subjects provides the first genetic evidence that leptin is an important regulator of energy balance in humans.

In 1994, two different strains of $o b / o b$ mice were reported to have defects in the gene encoding leptin, a previously unknown secreted fat-cell product ${ }^{1}$. Leptin is thought to act primarily at the hypothalamus, where it has effects on appetite, energy expenditure and neuroendocrine axes ${ }^{2-4}$. Treatment of $o b / o b$ mice with biosynthetic leptin corrects all of their phenotypic abnormalities ${ }^{5-7}$. Further, the administration of large amounts of leptin to normal rats and mice markedly reduces body fat stores, suggesting that, at least in rodents, leptin may influence body fat mass across a range of serum concentrations $^{8}$. A role for leptin deficiency in human obesity has been considered but no pathogenic mutations in the gene that encodes leptin have previously been found in obese humans ${ }^{9,10}$. Despite considerable evidence that genetic factors contribute to human obesity ${ }^{11}$, no mutations in any gene have been reported to cause obesity in humans. We have studied two related children with 